\title{
Rare Case of Membranous Obstruction at the Origin of Left Pulmonary Artery: Role of Perioperative Echocardiography to Evaluate the Anatomy of Pulmonary Artery
}

\author{
${ }^{1}$ Imran H Bhat, ${ }^{2}$ Srinath Damodaran, ${ }^{3}$ Banashree Mandal
}

\begin{abstract}
Branch pulmonary artery (PA) stenosis may occur as an isolated finding or in conjunction with other cardiac malformations; it may be congenital or acquired postoperatively. Branch PAs need to be assessed individually to determine the adequacy of their size, whether they are confluent or nonconfluent, any stenosis at origin or distally, and severity of stenosis. Certain lesions, such as supravalvar pulmonary stenosis, or stenosis at the branch PAs bifurcation, are better dealt with at surgery. Thus, perioperative transthoracic and transesophageal echocardiography (TEE) assume a very important role in precisely evaluating the anatomy of main and branch PAs.
\end{abstract}

Keywords: Branch pulmonary artery stenosis, Intracardiac repair, Left pulmonary artery stenosis, Tetralogy of Fallot, Transesophageal echocardiography.

How to cite this article: Bhat IH, Damodaran S, Mandal B. Rare Case of Membranous Obstruction at the Origin of Left Pulmonary Artery: Role of Perioperative Echocardiography to Evaluate the Anatomy of Pulmonary Artery. J Perioper Echocardiogr 2017;5(2):74-76.

Source of support: Nil

Conflict of interest: None

\section{INTRODUCTION}

Peripheral branch pulmonary artery stenosis (PPAS) may present as a physiologic benign lesion in neonates or as a specific pathological entity in $2 \%-3 \%$ of patients with congenital heart disease. ${ }^{1}$ PPS may present as an isolated finding at single or multiple sites, or may be associated with other cardiovascular malformations, such as variant of tetralogy of Fallot. Pathologically, PPS can be classified as congenital or acquired. Congenital PPS has been observed in congenital syndromes, such as Williams, Alagille, Keutel, Cutis laxa, Noonan, Rubella, and Ehler-Danlos

\footnotetext{
1,2Senior Resident, ${ }^{3}$ Associate Professor

${ }^{1-3}$ Department of Anesthesia and Intensive Care, Postgraduate Institute of Medical Education and Research, Chandigarh, India

Corresponding Author: Imran H Bhat, Senior Resident Department of Anesthesia and Intensive Care, Postgraduate Institute of Medical Education and Research, Chandigarh, India Phone: +917528978607, e-mail: imranbhat.005@gmail.com
}

syndromes. ${ }^{2-5}$ Acquired PPS may present following cardiac surgery or may be observed in rare conditions such as fibrosing mediastinitis or mediastinal tumors, which can cause PPS by external compression.

Four types of pulmonary artery stenosis, based on the location, have been described: ${ }^{3-5}$

1. Stenosis of the pulmonary trunk

2. Stenosis of the PA bifurcation with extension into right or left branch PA

3. Multiple peripheral PA stenosis

4. Stenoses of both the pulmonary trunk and peripheral arteries

Isolated PPAS has been observed in $40 \%$ of cases; while as $60 \%$ cases of PPAS have been reported to be associated with other cardiovascular defects (valvular pulmonary stenosis, atrial septal defect, ventricular septal defect, and patent ductus arteriosus). At least $20 \%$ of patients with tetralogy of Fallot have associated PPAS. Rare associations have been described with mitral stenosis or transposition of the great arteries. Peripheral pulmonary artery stenosis often presents in combination with supravalvular aortic stenosis or signs of other left-sided peripheral arteriopathy, such as in patients with Williams' syndrome. ${ }^{4}$ PPAS was recently included in the latest classification of pulmonary hypertension (PH - Nice, 2013) as part of group 5 ( $\mathrm{PH}$ with unclear multifactorial mechanism), under the name "segmental $\mathrm{PH}^{\prime} .{ }^{6}$

\section{CASE REPORT}

We report the case of 3 years old male child diagnosed with TOF (tetralogy of Fallot), scheduled for intra-cardiac repair. The preoperative echocardiogram revealed a 10 $\mathrm{mm}$ subaortic ventricular septal defect (VSD) with bidirectional shunting, $>50 \%$ aortic over ride, right ventricular (RV) hypertrophy, valvular and infundibular pulmonary stenosis and good sized confluent pulmonary arteries with normal biventricular function. These findings were confirmed on pre-operative transthoracic echocardiography in operation theatre, except that the left pulmonary artery wasn't visualized in standard imaging planes but was visualized in off axis imaging planes. The continuity of main pulmonary artery into right pulmonary artery 


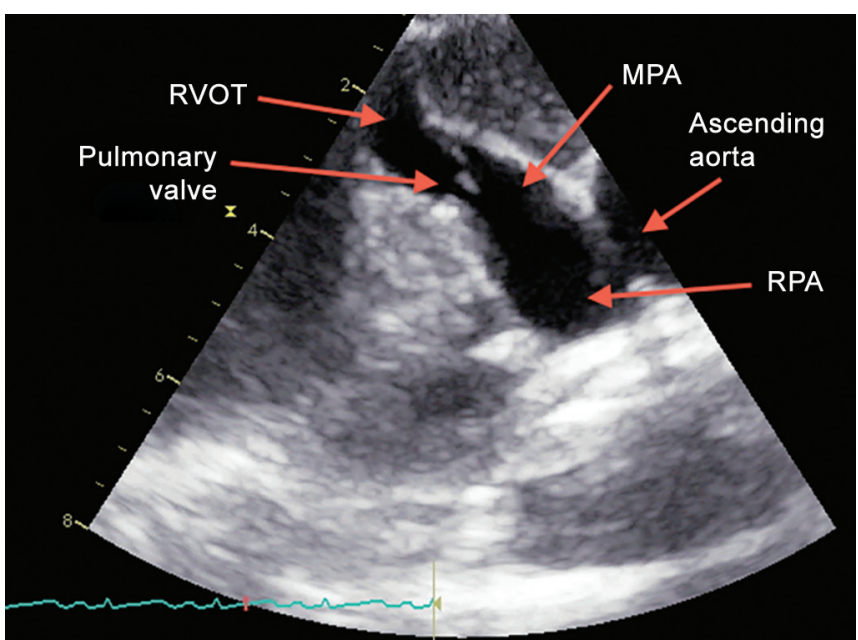

Fig. 1: Parasternal long-axis RV outflow tract view showing RV outflow tract, PV, MPA, right pulmonary artery (RPA), and ascending aorta

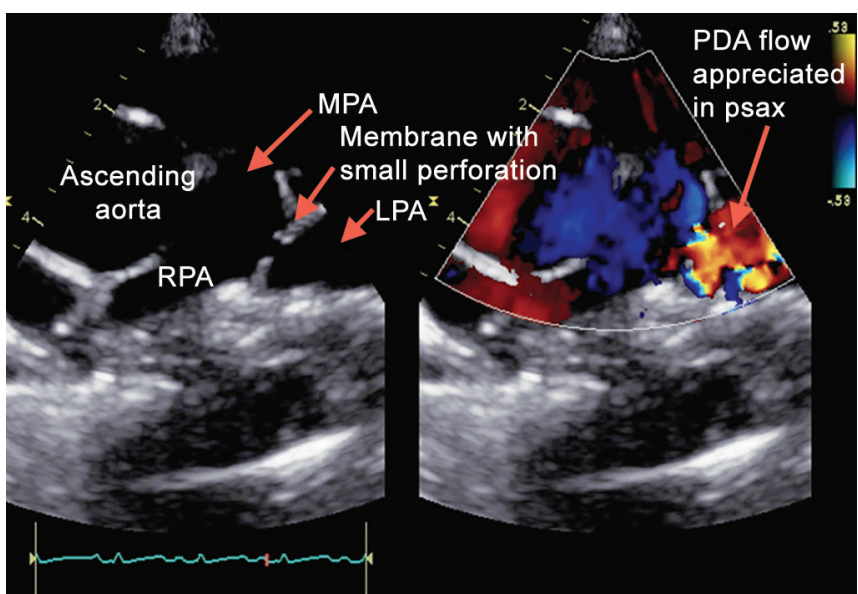

Fig. 3: High parasternal view showing perforated membrane at LPA origin, PDA flow into LPA, MPA, and right pulmonary artery (RPA)

was appreciated in parasternal short axis and parasternal long axis views but left pulmonary artery wasn't appreciable in either of the views (Fig. 1). After obtaining the right ventricular outflow tract view, the probe was slightly rotated clockwise to visualize LPA (Fig. 2). A membrane between main pulmonary artery (MPA) and left pulmonary artery (LPA) was appreciated at the origin of left pulmonary artery. Even from the standard parasternal short axis view, the origin of LPA from MPA was not appreciated. From off-axis high parasternal short axis view, the origin of LPA, the membrane between MPA and LPA, patent ductus arteriosus (PDA) supplying the LPA were visualized (Fig. 3). The flow of PDA into the LPA was confirmed after applying color and pulse wave Doppler (Fig. 4). These findings were confirmed on TEE (Fig. 5). The peak velocity and peak gradient across RVOT measured were $4.5 \mathrm{~m} / \mathrm{s}$ and $90 \mathrm{mmHg}$ respectively and no gradient was appreciated across the membrane between

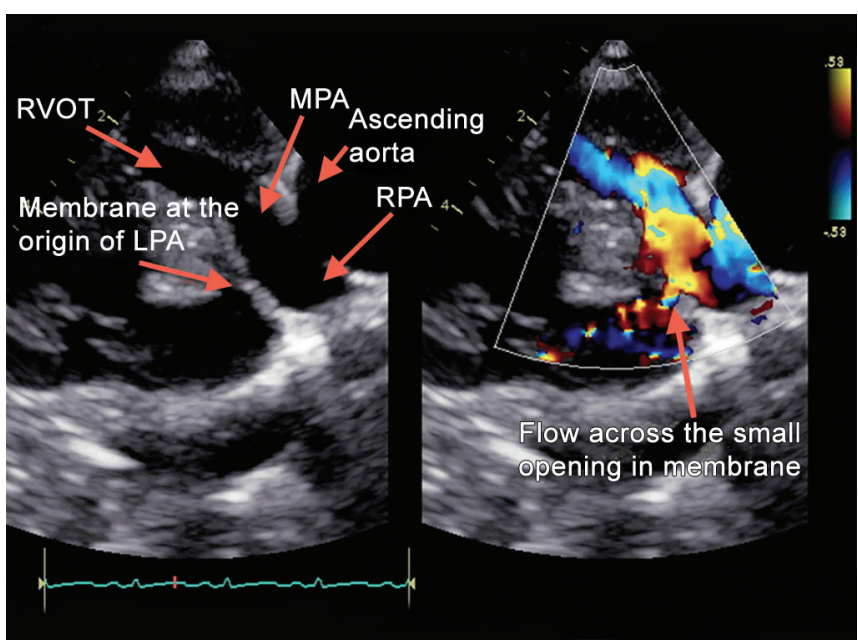

Fig. 2: Image obtained in off-axis plane from parasternal long-axis view with more angulation and clockwise rotation. A membrane with a small opening (as seen on color Doppler) at the origin of LPA, separating it from MPA, is seen

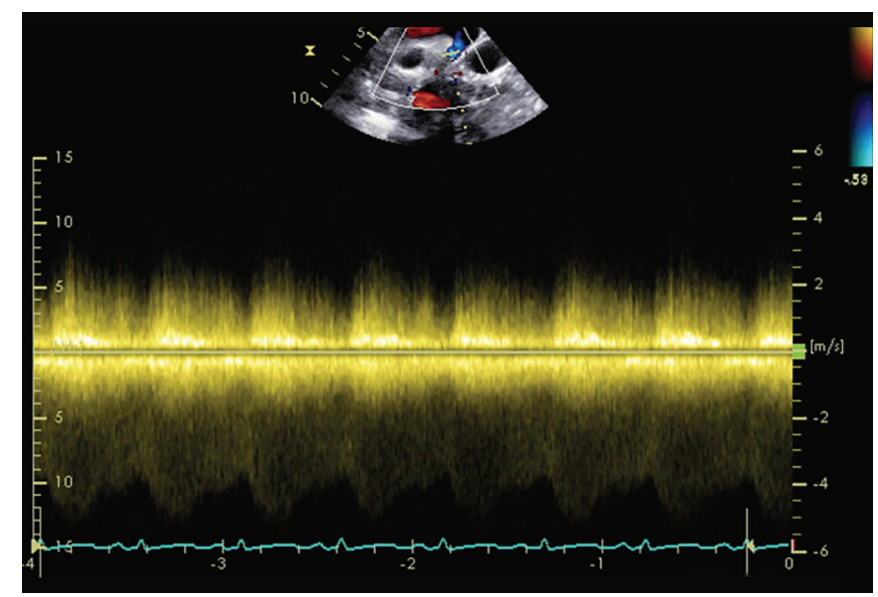

Fig. 4: Characteristic flow pattern of PDA obtained from suprasternal view

MPA and LPA, rather a continuous flow of PDA was appreciated in the LPA

\section{DISCUSSION}

Two-dimensional trans-esophageal and transthoracic echocardiography is used to evaluate the branch pulmonary arteries in children before and after repair of TOF.? Although the right pulmonary artery is adequately visualized in upper esophageal or parasternal/high parasternal echocardiographic views, the left pulmonary artery may less frequently be visualized in the upper esophageal or parasternal/high parasternal echocardiographic views. In most of the cases, the right and left pulmonary arteries are clearly imaged in parasternal long and short axis views by the usual technique or slight modification of the position and direction of transducer. With the aid of the sensitive color Doppler technique, area/areas of mosaic pattern identify the site/s of stenosis and application of 


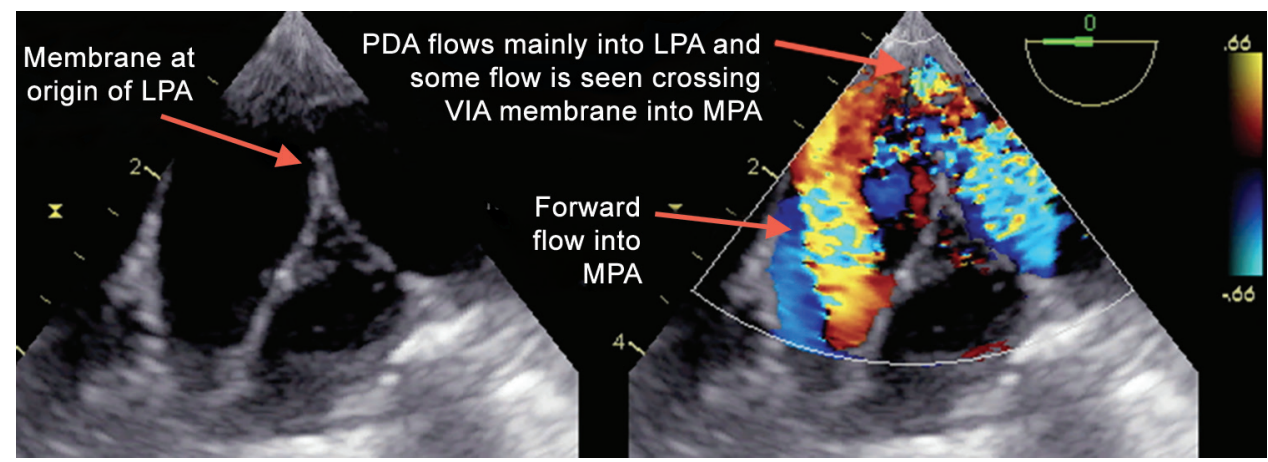

Fig. 5: Upper esophageal ascending aortic short-axis view with focus on PAs. The MPA, LPA, the perforated membrane, and juxta-membrane flow of PDA are appreciated in this imaging plane

continuous wave color Doppler assesses the peak and mean gradients across the stenosis. ${ }^{8}$

It is not uncommon to find primary or secondary branch pulmonary artery stenosis following palliative or corrective surgery for tetralogy of Fallot (TOF). The presence of branch pulmonary artery stenosis in the postoperative period may increase the morbidity and mortality of the patients. Thus identifying such lesions in the perioperative period may improve the patient outcome as the additional surgical and cardiac interventional procedures will be required to correct such abnormalities. Thus echocardiographic identification of the anomaly in the operation theatre will avoid repetition of surgery and improve postoperative outcome., ${ }^{9,10}$

The PH due to PPAS result in RV-pressure overload and RV-dysfunction, therefore establishing an echocardiographic or angiographic diagnosis for elevated pulmonary artery systolic pressure will alter the course of management. ${ }^{11}$

The absence of continuity of blood flow into left pulmonary artery was what prompted us to further evaluate the pulmonary arteries. The importance of detailed evaluation of pulmonary arteries in our case lay in the fact that the identification of membrane/shelf at the origin of LPA prevented second run of cardiopulmonary bypass and RV hypertension and dysfunction in the postoperative period, thus preventing the associated morbidity had the stenosis not been addressed timely. The information conveyed resulted in modification of surgical plan from just resection of infundibular obstruction and placing a transanular patch to additionally resect the membrane/ shelf at the origin of LPA. Thus dreadful consequences of persistent RV hypertension, RV dysfunction, complete obstruction of blood flow to LPA/ left lung after the ligation of PDA were prevented.

\section{REFERENCES}

1. Rodriguez RJ, Riggs TW. Physiologic peripheral pulmonic stenosis in infancy. Am J Cardiol 1990 Dec;66(20):1478-1481.

2. Lock JE, Castaneda-Zuniga WR, Fuhrman BP, Bass JL. Balloon dilation angioplasty of hypoplastic and stenotic pulmonary arteries. Circulation 1983 May;67:962-967.

3. Franch RH, Gay BB Jr. Congenital stenosis of the pulmonary artery branches. Am J Med 1963 Oct;35:512-529.

4. Beuren AJ. The syndrome of supravalvular aortic stenosis, peripheral pulmonary artery stenosis, mental retardation, and similar facial appearance. Am J Cardiol 1964 Apr; 13(4):471-483.

5. Kim YM, Yoo SJ, Choi JY, Kim SH, Bae EJ, Lee YT. Natural course of supravalvar aortic stenosis and peripheral pulmonary arterial stenosis in William's syndrome. Cardiol Young 1999 Jan;9(1):37-41.

6. Simonneau G, Gatzoulis MA, Adatia I, Celermajer D, Denton C, Ghofrani A, Gomez Sanchez MA, Krishna Kumar R, Landzberg M, Machado RF, et al. Updated clinical classification of pulmonary hypertension. J Am Coll Cardiol 2013 Dec;62(25 Suppl):D34-D41.

7. Tonelli AR, Ahmed M, Hamed F, Prieto LR. Peripheral pulmonary artery stenosis as a cause of pulmonary hypertension in adults. Pulm Circ 2015 Mar;5(1):204-210.

8. Hiraishi S, Misawa H, Hirota H, Agata $Y$, Horiguchi $Y$, Fujino N, Yi LH, Yashiro K, Nakae S, Kawada M. Noninvasive quantitative evaluation of the morphology of the major pulmonary artery branches in cyanotic congenital heart disease. Angiocardiographic and echocardiographic correlative study. Circulation 1994 Mar;89(3):1306-1316.

9. Cohn LH, Sanders JH Jr, Collins JJ Jr. Surgical treatment of congenital unilateral pulmonary artery stenosis with contralateral pulmonary hypertension. Am J Cardiol 1976 Aug;38(2):257-260.

10. Rocchini AP, Kveselis D, Dick M, Crowley D, Snider AR, Rosenthal A. Use of balloon angioplasty to treat peripheral pulmonary stenosis. Am J Cardiol 1984 Nov;54(8):1069-1073.

11. O'Laughlin MP, Slack MC, Grifka RG, Perry SB, Lock JE, Mullins CE. Implantation and intermediate-term followup of stents in congenital heart disease. Circulation 1993 Aug;88:605-614. 